
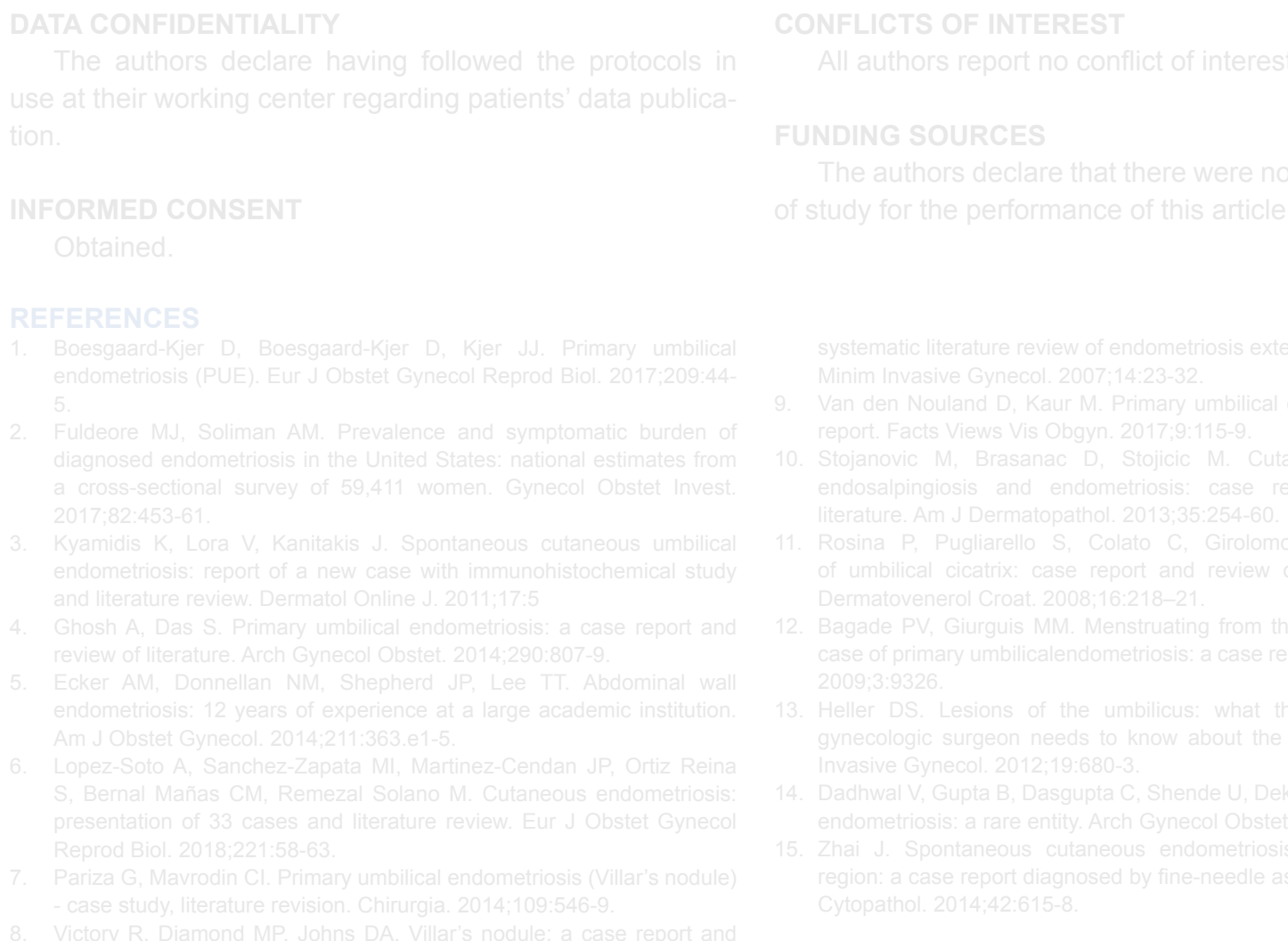

FUNDING SOURCES

\title{
Um Afrodisíaco Potencialmente Fatal: Intoxicação por Cantaridina
}

\author{
A Potentially Fatal Aphrodisiac: Cantharidin Poisoning
}

Priscila DIAZ $\rrbracket^{1}$, António CARNEIRO ${ }^{1}$, Vera MONTES ${ }^{2}$, Sara ALVES ${ }^{3}$

Acta Med Port 2020 Apr;33(4):284-287 - https://doi.org/10.20344/amp.11567

\section{RESUMO}

A cantaridina é uma toxina extraída de coleópteros, comummente conhecidos como 'Spanish fly'. Historicamente utilizada como afrodisíaco, vesicante e abortivo. A intoxicação por este agente encontra-se amplamente descrita, tipicamente com envolvimento das mucosas gastrointestinal, com hemorragia digestiva, e genitourinária, com hematúria e lesão renal aguda. Os autores apresentam o caso de um doente do sexo masculino, com 51 anos que desenvolveu um quadro de intoxicação aguda por cantaridina, após ingestão de uma preparação ('chá') desta substância, com ardor na cavidade oral, diarreia, disúria, hematúria, lesão renal aguda e com um quadro neurológico atípico. A toxicidade pela cantaridina é sistémica, contudo, o envolvimento neurológico é raro. Dada ausência de um antídoto, preconiza-se a terapêutica de suporte. Este caso reforça a importância de uma anamnese detalhada, incluindo a utilização de produtos 'naturais' ou de ervanária (i.e. de origem não controlada), e da necessidade de alertar os doentes para a sua potencial toxicidade.

Palavras-chave: Afrodisíacos; Cantaridina/toxicicidade; Dípteros; Intoxicação/etiologia

\section{ABSTRACT}

Cantharidin is a toxin extracted from coleoptera beetles, commonly known as 'Spanish fly'. Traditionally it was used as an aphrodisiac, a vesicant or as an abortifacient. Intoxication by this substance has been widely reported, generally associated with gastrointestinal complications, such as digestive hemorrhage, and genitourinary disorders, such as hematuria and acute kidney injury. The authors describe the case of a 51-year old male patient who developed severe cantharidin poisoning after ingesting a preparation ('tea formulation') containing the substance. The patient reported a burning sensation in his oral cavity, diarrhea and hematuria, having sustained acute kidney injury and atypical neurological symptoms. Due to the lack of an antidote, the available treatment options are reduced to supportive measures. This case strengthens the need for a thorough medical history to ascertain the use of 'natural' products and

1. Serviço de Medicina Interna. Hospital de Cascais. Cascais. Portugal.

2. Serviço de Neurologia. Hospital de Cascais. Cascais. Portugal.

3. Serviço de Medicina Interna. Hospital Fernando Fonseca. Amadora. Portugal.

$\bowtie$ Autor correspondente: Priscila Diaz. milenediaz22@gmail.com

Recebido: 16 de novembro de 2018 - Aceite: 10 de janeiro de 2019 | Copyright $\odot$ Ordem dos Médicos 2020 
medicinal herbs (i.e. of unregulated origin), and the importance of educating the community to their potential toxicity.

Keywords: Aphrodisiacs; Cantharidin/toxicity; Diptera; Poisoning/etiology

\section{INTRODUÇÃO}

A cantaridina é uma substância produzida por insectos da ordem Coleoptera, destacando-se as famílias Meloidae e Oedemeridae, das quais a espécie mais conhecida é a Lytta vesicatoria ou 'Spanish fly'.1-3 Tem sido classicamente utilizada como afrodisíaco e abortivo. ${ }^{1,2}$ Apresenta ainda um efeito vesicante quando utilizado topicamente, devido à acantólise intradérmica que provoca, pelo que é ainda utilizado como medicamente no tratamento de verrugas e molusco contagioso e vesicante. ${ }^{1,2} \mathrm{O}$ seu efeito afrodisíaco é um mito, provavelmente induzido pela observação de congestão pélvica e priapismo na intoxicação, e a sua ingestão com esta intenção é a que se associa frequentemente com intoxicações graves ou fatais. ${ }^{4} \mathrm{O}$ seu potencial terapêutico como citostático tem sido estudado e proposto, mas é atualmente limitado pela sua elevada toxicidade. . $^{3,5,6}$

\section{CASO CLÍNICO}

Os autores apresentam o caso de um doente do sexo masculino, com 51 anos, leucodérmico, autónomo, com história pessoal conhecida de dislipidémia mista, medicado com rosuvastatina e fenofibrato, e hábitos toxifílicos cessados há mais de 10 anos (cocaína e heroína). Admitido no serviço de urgência por sensação de ardor na cavidade oral, hipogeusia, hiposmia, vómitos, diarreia, disúria e hematúria com dois dias de evolução. Foi apurada a ingestão de "chá afrodisíaco", que se revelou conter cantaridina, adquirido em mercado não regulado (uma colher de chá do preparado dissolvida numa chávena de água), com consumo imediatamente antes do início dos sintomas. À observação encontrava-se taquicárdico (105 bpm) e desidratado. A gasimetria de sangue arterial revelou uma acidémia metabólica com gap aniónico aumentado (Tabela 1) e, analiticamente, apresentava uma lesão renal aguda com elevação dos parâmetros inflamatórios (Tabela 2). Foram realizadas hemoculturas e urocultura. Adicionalmente, realizou uma tomografia abdomino-pélvica, que não revelou alterações de relevo.

Tabela 1 - Gasimetria de sangue arterial $\left(\mathrm{FiO}_{2} 21 \%\right)$, à admissão

\begin{tabular}{lcc}
\hline $\mathrm{pH}$ & 7.34 & {$[7,35-7,45]$} \\
$\mathrm{pO}_{2}$ & $87,2 \mathrm{mmHg}$ & {$[80-100]$} \\
$\mathrm{pCO}_{2}$ & $30,3 \mathrm{mmHg}$ & {$[35-45]$} \\
$\mathrm{HCO}_{3}-$ & $16,1 \mathrm{mmol} / \mathrm{L}$ & {$[23-29]$} \\
$\mathrm{SatO}_{2}$ & $95,8 \%$ & {$[95 \%-97 \%]$} \\
$\mathrm{Na}^{+}$ & $137 \mathrm{mmol} / \mathrm{L}$ & {$[134-146]$} \\
$\mathrm{K}^{-}$ & $3,7 \mathrm{mmol} / \mathrm{L}$ & {$[3,4-5,0]$} \\
$\mathrm{Ca}^{++}$ & $0,96 \mathrm{mmol} / \mathrm{L}$ & {$[1,1-1,35]$} \\
$\mathrm{Cl}$ & $95 \mathrm{mmol} / \mathrm{L}$ & {$[98-106]$} \\
Excesso de base & $-7,7 \mathrm{mmol} / \mathrm{L}$ & {$[-2 /+2]$} \\
Gap aniónico & $24 \mathrm{mEq} / \mathrm{L}$ & {$[8-16]$} \\
Lactato & $2,43 \mathrm{mmol} / \mathrm{L}$ & {$[0,5-1,6]$} \\
Glucose & $136 \mathrm{mg} / \mathrm{dL}$ & {$[70-105]$} \\
\hline
\end{tabular}

Foi assumida intoxicação por cantaridina com lesão renal aguda AKIN III. Os exames culturais foram negativos. Sob medidas de suporte, apresentou recuperação completa da função renal, com diurese mantida, sem necessidade de terapêutica de substituição renal. Contudo, desenvolveu um quadro neurológico exuberante, com parestesias ao nível dos membros inferiores e síndrome confusional aguda, com desorientação e alucinações visuais complexas, com resposta favorável à terapêutica neuroléptica, mantendo a anosmia e hipogeusia, inicialmente referidas. Ao exame neurológico destacava-se hipostesia álgica da face e extremidades dos quatro membros, com compromisso marcado da sensibilidade profunda dos membros inferiores, com marcha atáxica (tipo sensorial). Realizou ressonância magnética cranioencefálica e electromiografia dos membros que não revelaram alterações de relevo. $O$ doente iniciou um programa vigoroso de reabilitação motora, com melhoria clínica; aos seis meses após alta, com recuperação significativa da sensibilidade, com marcha autónoma, contudo, mantendo hemiataxia direita sensorial, sem outros défices neurológicos.

\section{DISCUSSÃO}

A cantaridina é uma substância cuja toxicidade é relatada episodicamente em contexto de consumo tradicional. À temperatura ambiente, é um sólido incolor, inodoro e insípido, solúvel em solventes orgânicos como éter, clorofórmio e acetona, mas praticamente insolúvel em água. Devido à sua elevada estabilidade, pode permanecer intacta no insecto morto ou mesmo em alimentos contaminados. ${ }^{3} \mathrm{Re}-$ lativamente ao seu efeito a nível celular, vários estudos in vitro e in vivo, em animais, demonstraram uma elevada afinidade por proteínas fosfatases (PP, protein phosphatase) 1 a 5 , com inibição da sua actividade catalítica em vários órgãos, como coração, fígado e rim, e indução da apoptose celular. ${ }^{3,5-7}$ A cantaridina circula no sangue ligada à albumina e tem excreção renal (lenta). ${ }^{4}$

Tabela 2 - Estudo analítico à admissão

\begin{tabular}{lcc}
\hline Hemoglobina & $19,1 \mathrm{~g} / \mathrm{dL}$ & {$[13-18]$} \\
Hematócrito & $54,2 \%$ & {$[40-54]$} \\
Leucócitos & $17 \mathrm{100} / \mathrm{\mu L}$ & {$[4000-11000]$} \\
Plaquetas & $270 \mathrm{000} / \mathrm{\mu L}$ & {$[150000-40000]$} \\
Creatinina & $6,78 \mathrm{mg} / \mathrm{dL}$ & {$[0,70-1,30]$} \\
Ureia & $123 \mathrm{mg} / \mathrm{dL}$ & {$[<50]$} \\
Sódio & $135 \mathrm{mmol} / \mathrm{L}$ & {$[136-145]$} \\
Potássio & $3,99 \mathrm{mmol} / \mathrm{L}$ & {$[3,50-5,10]$} \\
Cloro & $95 \mathrm{mmol} / \mathrm{L}$ & {$[96,0-107,0]$} \\
CK & $738 \mathrm{UI} / \mathrm{L}$ & {$[39,0-308,0]$} \\
LDH & $647 \mathrm{UI} / \mathrm{L}$ & {$[87-241]$} \\
PCR & $9,37 \mathrm{mg} / \mathrm{dL}$ & {$[<0,3]$} \\
\hline CK: Creatina &
\end{tabular}

CK: creatinina quinase; $\mathrm{LDH}$ : lactato desidrogenase; $\mathrm{PCR}$ : proteína $\mathrm{C}$ reactiva 
A intoxicação por esta substância tem sido amplamente descrita e pode ocorrer através do contacto com mucosas, pele ou por ingestão (com uma dose mínima de $10 \mathrm{mg}),{ }^{8}$ com uma dose letal média estimada em $1 \mathrm{mg} / \mathrm{kg}$. Os sintomas parecem surgir entre duas a 14 horas após exposição ao tóxico. ${ }^{2,9} \mathrm{Em}$ termos da sua toxicidade por sistema de órgão, descreve-se:

- Gastrointestinal: sensação de ardor ao nível da orofaringe com lesões bolhosas, disfagia, dor abdominal, vómitos, mucosite hemorrágica do tracto gastrointestinal com hematemeses e hematoquézias, diarreia ${ }^{2,4}$;

- Genitourinária: destacando-se a lesão renal aguda frequentemente oligo-anúrica, por necrose tubular aguda e destruição glomerular (congestão tubular secundária a descamação tubular renal, edema da membrana glomerular); tipicamente, cursa com disúria, hematúria, ${ }^{7,10}$ priapismo e dor pélvica, por congestão vascular, ${ }^{2}$ e, por vezes, metrorragias ${ }^{4}$;

- Cardíaca: com perturbação do ritmo cardíaco (sendo a taquicardia sinusal a manifestação mais frequente), com instabilidade do segmento ST e disritmias ventriculares (por vasoconstrição coronária) $)^{8,11}$; alguns relatos de autópsias descrevem focos hemorrágicos do subendocárdio e pericárdio ${ }^{4,11}$; a miotoxicidade parece ocorrer por inibição das fosfatases 1 e 2a, e não por interferência directa no cálcio intracelular ${ }^{11}$;

- Cutânea: por degeneração da placa desmossomal, com irritação local, acantólise e desenvolvimento de lesões vesicobolhosas ou ulceradas ${ }^{1,4}$;

- Neurológica: com alteração do estado de consciência, hipertonia, hiperreflexia, crises epilépticas, ataxia, polineuropatia inflamatória periférica; geralmente, não são reportadas alterações do estudo líquido cefalorraquidiano; algumas autópsias relatam equimoses das meninges e petéquias cerebrais ${ }^{3,4,9}$;

- Sintomas constitucionais: febre ${ }^{9}$;

- Hematológica: anemia, leucocitose, trombocitopenia, ${ }^{9}$ coagulação intravascular disseminada 4 ;

- Respiratória: descrita raramente, com edema pulmonar não cardiogénico, hemorragia brônquica e subpleural. ${ }^{4}$

O diagnóstico baseia-se na anamnese, dada ausência de um método específico de detecção do tóxico no sangue, tecidos ou fluidos corporais; a sua identificação em laboratório é possível através de métodos de difração de raio-X, microsublimação ou processamento complexo dos órgãos afectados, ${ }^{12}$ ou cromatografia gasosa e espectroscopia de massa. ${ }^{4}$

Dada a ausência de um antídoto, o tratamento actualmente preconizado é de suporte. A absorção pelo tubo digestivo parece ser reduzida pela administração de carvão e aumentada por gorduras, ${ }^{3}$ pelo que o doente deve ingerir água em abundância e evitar alimentos gordurosos. O vómito também não deve ser induzido para evitar novo dano esofágico. ${ }^{1} \mathrm{~A}$ terapêutica de substituição renal não parece oferecer benefício significativo dada a elevada afinidade da cantaridina para a albumina. ${ }^{4}$

\section{CONCLUSÃO}

Este caso pretende ilustrar a tendência não negligenciável da população actual para o consumo de produtos de origem não controlada com uma exposição crescente aos seus efeitos tóxicos, e do papel central da anamnese rigorosa que permita um diagnóstico adequado e atempado. A intoxicação por cantaridina será um exemplo paradigmático desta problemática, sobretudo, dada a sua elevada toxicidade sistémica, com especial destaque para o envolvimento neurológico acima reportado, raramente descrito na literatura.

\section{PROTEÇÃO DE PESSOAS E ANIMAIS}

Os autores declaram que os procedimentos seguidos estavam de acordo com a Declaração de Helsínquia da Associação Médica Mundial.

\section{CONFIDENCIALIDADE DOS DADOS}

Os autores declaram ter seguido os protocolos de garantia de confidencialidade de dados pessoais.

\section{CONFLITOS DE INTERESSE}

Os autores declaram conflitos de interesse.

\section{CONSENTIMENTO INFORMADO}

Obtido.

\section{FONTES DE FINANCIAMENTO}

Este trabalho não recebeu qualquer tipo de suporte financeiro de nenhuma entidade do domínio público ou privado.

of aberrant mitotic spindles and lagging chromosomes resulting, in part, from the suppression of PP2Aa. Mol Cancer Ther. 2006;5:2727-36.

6. Li HC, Xia ZH, Chen YF, Yang F, Feng W, Cai H, et al. Cantharidin inhibits the growth of triple-negative breast cancer cells by suppressing autophagy and inducing apoptosis in vitro and in vivo. Cell Physiol Biochem. 2017;43:1829-40.

7. Massicot F, Dutertre-Catella H, Pham-Huy C, Liu XH, Duc H, Warnet $\mathrm{J}$. In vitro assessment of renal toxicity and inflammatory events of two protein phosphatase inhibitors cantharidin and nor-cantharidin. Basic Clin Pharmacol Toxicol. 2005;96:26-32.

8. Nyazema N. Cantharidin poisoning: a review. SA Fam Pract. 1989;10:70- 
3.

9. Binali A, Shabana M, Fifi S, Dawood S, Shehri A, Barki A. Cantharidin poisoning due to blister beetle ingestion in children. Sultan Qaboos Univ Med J. 2010;10:258-61.

10. Smith RM. The origin of urinary casts; an experimental study. Boston
Med Surg J. 1908:158:696-701.

11. Knapp J, Bokník P, Huke S, Lüss $H$, Müller FU, Müller T, et al. The mechanism of action of cantharidin in smooth muscle. $\mathrm{Br} \mathrm{J}$ Pharmacol. 1998;123:911-9.

12. Nickolls LC, Teare D. Poisoning by cantharidin. BMJ. 1954;2:1384-6. 